\title{
The Study of the Mineral and Chemical Features of the Trans-Baikal Basalt Deposit to Generate Melt Using the Electric Arc Method
}

\author{
S.L. Buyantuev, A.S. Kondratenko, A.B. Khmelev, \\ E.T. Bazarsadaev and S.A. Blagochinov \\ East-Siberian State University of Technologies and Management \\ 670013, Ulan-Ude, Russia, 40V Klyuchevskaya Street \\ http://dx.doi.org/10.13005/bbra/2133
}

(Received: 02 February 2016; accepted: 04 April 2016)

\begin{abstract}
The article presents the results of the mineral and chemical study of basaltic rocks of the Selendumsky deposit with its further melting in electric arc plasma to generate melt, obtain stone cast and fibrous materials based on it. To conduct tests on melt generation the processing samples of the Selendumsky basalt deposit of Transbaikalia were used, sieve analysis of the samples showed that the main part of its mass is represented by particles ranging in size from 7.0 to $1.0 \mathrm{~mm}(90.35 \%)$. The study of basalt in thin sections revealed that there are lenticular textures leading to the appearance of small zones of tectonic crushing and cataclase. The studies of the mineral and chemical composition revealed that in obtaining of the melt and generating of the mineral fiber composition from it the Selendumsky basalt for its composition is included in the following limits: $\mathrm{SiO} 247,5-55,0 ; 14,0-20,0$ Al2O3; 3,0-8,5 MgO; 7, -11.0 CaO; other rocks (no more than $5 \%$ ). For the research on the generation of basalt melts an electromagnetic process reactor with working regimes of melting was applied. When studying the melting mechanism of the raw material using the electric arc melting apparatus a simulation environment was used in terms of the TEPPA computer program.
\end{abstract}

Key words: Basalt raw material, mineralogical, chemical and phase compositions, electric arc plasma, electromagnetic apparatus, microscopic analysis, melt, fiber.

The demand for products made of basalt raw materials (mineral wool, stone cast) widely used in industry, construction, energy and other spheres of production is constantly increasing. There is a growing degree of technological improvement in the basalt production. At the same time the mining base that provides production of the basalt raw material of high quality falls behind. The main reason for this condition is the failure to recognize the raw material for the production to basalt minerals. The use in the manufacture of the construction stone chip fiber of variable mineral and chemical composition negatively affects both the technology

\footnotetext{
* To whom all correspondence should be addressed.
}

of production, and the quality of the final product. However, it is known that the chemical and mineral composition of basalt raw materials has effect on the melt generation and fiber from it, in particular the presence of refractory minerals, metamorphism degree. The raw materials used for melting must be fusible, with rapid transition into melt without traces of primary crystal phase ${ }^{1}$.

Processing of basalt raw material into melt is an important scientific and technical issue, however, reduction of the energy consumption in the melts generation affecting the cost of production of mineral insulating materials was and remains the main problem.

One promising direction in this area is the use of electric arc plasma for the raw material melting to produce fibrous heat-insulating 
materials. When the electric arc used as the thermal energy source, due to the high temperature the melt obtaining time-point sharply decreases due to elimination of the induction period of melting 2 .

The work was carried out to study the mineral and chemical composition of the Selendumsky basalt in connection with the data for the melt obtaining using electric arc melting equipment.

\section{Methodology \\ Research materials}

To conduct tests on the melt generation the samples from the Selendumsky deposit basalt were used with the following particle size distribution (Table. 1).

Sieve analysis of the samples shows that most of its weight composition contains particle size from 7.0 to $1.0 \mathrm{~mm}$ (90.35\%). Particles smaller than $0.2 \mathrm{~mm}$ are less than $2 \%$.

In the macroscopic study, visually and by the structural features the individual differences are distinguished in the sample: aphonite basalts, anamizits and the actual basalt - fine- and medium grained rocks containing large amount of plagioclase [3]. The sample is mostly composed by intermediate in grain, mostly fine-grained, dense, hard effusive rocks of dark gray color, containing porphyritic plagioclase. The carbonate coat is often observed in the basaltoids cracks. Isolated fragments of basalts of greenish-gray color, weaker, with the rough, earthy fracture surface are in the sample composition.

The study of basalt in thin sections revealed that it underwent the metamorphic transformation, during which lenticular textures appeared that lead to the appearance of the small zones of tectonic crushing and cataclase made by chlorite, carbonate and partially by quartz ${ }^{4}$.

Under the microscope (Figure 1) the fractures of the basic rocks of the basaltoid set can be seen in the following percentages: plagioclase - 40-60\%; pyroxene - $15-20 \%$; highly reflective medium-grained quartz dolerite (break glass) - $10-15 \%$ olivine $5-10 \%$, 8-14\% ore minerals, chlorite $1-5 \%$. Porphyritic crystals of clinopyroxene and plagioclase, usually, that underwent crushing, are replaced by chlorite in the cracks, and in the marginal parts are surrounded by the inner rim of fine lamellar chlorite of black and dark gray color. Dolerites are mostly porphyritic and olivine. The structure is porphyritic alternating with ophitic and tholeiitic structures of the bulk.

The chemical analysis is one of the main research methods of the mineral composition of raw materials ${ }^{5}$. To determine the chemical composition an averaged (quarter) sample was selected. The analysis was made in accordance with GOST 10538-87, which stipulated determination of ten main components of the raw material: $\mathrm{SiO}_{2} ; \mathrm{Al}_{2} \mathrm{O}_{3} ; \mathrm{FeO}+\mathrm{Fe}_{2} \mathrm{O}_{3} ; \mathrm{CaO} ; \mathrm{MgO}$; $\mathrm{SO}_{3} ; \mathrm{TiO}_{2} ; \mathrm{Na}_{2} \mathrm{O}+\mathrm{K}_{2} \mathrm{O} ; \mathrm{P}_{2} \mathrm{O}_{5}$. Table 2 shows the chemical composition of the Selendumsky deposit basalt and for comparison the data of other basalt deposits is shown.

The studies revealed that to obtain melt and generate mineral fibers from it the Selendumsky basalt by its chemical composition can be included in the following limits: $\mathrm{SiO}_{2} 47,5-55,0 ; 14,0-20,0$ $\mathrm{Al}_{2} \mathrm{O}_{3} ; 3,0-8,5 \mathrm{MgO} ; 7,-11.0 \mathrm{CaO}$; other rocks (no more than 5\%). Thus, the given raw material is fundamentally suitable for the melt obtaining and mineral wool by electrothermal method ${ }^{6}$.

The experimental setup for raw materials melting Rocks (basalt) containing refractory minerals for melts generating are hardly processed in the "classic" melting aggregates (cupola, bathroom and tunnel glass furnaces) due to the low temperatures generated by it (up to 2000 0C) so the industrial processing of this type of the raw material can be realized by electric arc (plasma) or induction (UHF) methods, however, induction furnaces due to high energy costs, strong electromagnetic radiation and radio interference caused by it, as well as the risk of explosion of the inductor in the case of short circuit, are limitedly used in the industry. Electric arc plasma devices are preferred in refractory materials melting thanks to special properties of plasma, such as: high temperature (up to $5000 \mathrm{~K}$ ), specific power per unit volume of the reactor and, consequently, process speed, presence of large amount of electrons, ions and free radicals in the bulk of the reactor causing rapid melting of the treated material. In contrast to the cupola and bath methods the electrothermal method can reduce costs of equipment and facilitate its use.

For the research on the generating of basalt melts from raw materials an electromagnetic process reactor was used as melter with working regimes of melting (Figure 2).

The design features of the reactor allow 
to obtain clean melt, free from occluded gases and reduced metals, enabling the production of products of higher quality.

\section{RESULTSAND DISCUSSION}

For obtaining of computational, theoretical and experimental results on the basalt melting with determination of optimum technological modes in the preparation of the melts it is necessary to carry out calculations of hightemperature melting (refining) of this raw material. When studying the melting mechanism of the raw material with the help of the electric arc melting apparatus a simulation environment was used in terms of the TEPPA computer program ${ }^{7}$.

The described software package allows to simulate the maximum equilibrium states and sets the created method and the algorithm of calculations into effect. For each matter the set of

Table 1. Sieve analysis of the Selendumsky basalt

\begin{tabular}{lcccccccc}
\hline ClASS SIZE, MM & +7 & $-7+5$ & $-5+2,5$ & $-2,5+1$ & $-1+0,5$ & $-0,5+0,3$ & $-0,3+0,2$ & 0,2 \\
\hline Yield\% & 4,95 & 28,10 & 38,75 & 18,55 & 3,65 & 2,75 & 1,49 & 1,86 \\
\hline
\end{tabular}

Table 2. The chemical composition of basalts from various deposits proportion of components \%Basalts

Selendumsky Marneuli Berestovetsky (Russia, Baikal), (Georgia) (Ukraine)

\begin{tabular}{lccc}
\hline $\mathrm{SiO}_{2}$ & 48,12 & 46,0 & 49,03 \\
$\mathrm{Al}_{2} \mathrm{O}_{3}$ & 13,87 & 16,75 & 12,58 \\
$\mathrm{TiO}_{2}$ & 2,93 & 1,13 & 2,85 \\
$\mathrm{Fe}_{2} \mathrm{O}_{3}$ & 5,28 & 6,66 & 3,88 \\
$\mathrm{FeO}$ & 6,74 & 3,60 & 10,15 \\
$\mathrm{CaO}$ & 8,80 & 9,07 & 9,53 \\
$\mathrm{MgO}$ & 3,75 & 4,65 & 5,47 \\
$\mathrm{Na}_{2} \mathrm{O}$ & 3,37 & 3,88 & 2,34 \\
$\mathrm{~K}_{2} \mathrm{I}$ & 1,72 & 1,00 & 0,66 \\
$\mathrm{MnO}^{2} \mathrm{O}$ & 0,17 & 0,18 & 0,32 \\
$\mathrm{P}_{2} \mathrm{O}_{5}$ & 0,78 & 0,40 & 0,30 \\
$\mathrm{SO}_{3}$ & 0,21 & 0,24 & 0,21 \\
\hline
\end{tabular}

properties must consist of its chemical formula, the limits of approximation of thermodynamic functions Tmin, Tmax, seven coefficients for the given thermodynamic potential $\mathrm{Fi}(\mathrm{T})(\varphi 1$ - $\varphi \mathrm{i})$, the standard enthalpy of formation Hf0 (298). Each individual substance in the database of the TERRA program corresponds to one or several sets of properties, in addition to the indicated thermodynamic functions the parameters of Lennard-Jones function for calculation of the thermal constants (coefficients of thermal conductivity, viscosity, diffusion) of multicomponent gas mixtures are included in the above features.

The specific energy consumption for the heat treatment process consists of energy input for heating of the raw material to a predetermined

Table. 3 The composition of the condensed phases of the Selendumsky basalt deposit

\begin{tabular}{lccccccccc}
\hline \multirow{2}{*}{$\begin{array}{l}\text { Heating } \\
\text { temp., }\end{array}$} & \multicolumn{7}{c}{ The composition of the condensed phases of the selendumsky basalt deposit \% } \\
\cline { 2 - 10 } & $\mathrm{SiO}_{2}$ & $\mathrm{Al}_{2} \mathrm{O}_{3}$ & $\mathrm{Fe}_{2} \mathrm{O}_{3}$ & $\mathrm{TiO}_{2}$ & $\mathrm{CaSiO}_{3}$ & $\mathrm{CaTiO}_{3}$ & $\mathrm{MgSiO}_{3}$ & $\mathrm{~K}_{2} \mathrm{Si}_{4} \mathrm{O}_{9}$ & $\mathrm{Na}_{2} \mathrm{Si}_{2} \mathrm{O}_{5}$ \\
\hline 1000 & 26,5 & 14,48 & 13,3 & 3,0 & 17 & - & 9,7 & 5,4 & 7,7 \\
1200 & 26,5 & 14,48 & 13,3 & 3,0 & 17 & - & 9,7 & 5,4 & 7,7 \\
1400 & 28,8 & 14,48 & 13,3 & - & 12,5 & 5,2 & 9,7 & 5,4 & 7,7 \\
1600 & 28,8 & 14,48 & 13,3 & - & 12,5 & 5,2 & 9,7 & 5,4 & 7,8 \\
1800 & 31,5 & 14,48 & $\mathrm{Fe}_{3} \mathrm{O}_{4} 12,8$ & - & 12,5 & 5,2 & $\mathrm{Mg}_{2} \mathrm{SiO}_{4} 6,8$ & 5,4 & 8,2 \\
2000 & 27,4 & 14,48 & 12,8 & - & 17,5 & - & 7,8 & 5,2 & 8,1 \\
2200 & 27,4 & 14,48 & 12,8 & - & 19,5 & - & 7,8 & 4,4 & 7,7 \\
2400 & 27,4 & 14,48 & 12,8 & - & 19,5 & - & 7,8 & 4,5 & 7,6 \\
2600 & 27,4 & 14,48 & 12,8 & - & 19,5 & - & 7,8 & 4,5 & 7,5 \\
2800 & 27,8 & 14,48 & $\mathrm{FeO}_{2}, 0$ & - & 19,5 & - & 7,8 & 4,3 & 7,0 \\
3000 & 26,6 & 14,48 & $\mathrm{Fe}_{2} \mathrm{SiO}_{4} 15,7$ & - & 19,5 & - & 7,8 & 1,2 & - \\
\hline
\end{tabular}


Table 4. The dependence of the specific energy consumption of the basalt melting temperature

\begin{tabular}{|c|c|c|c|c|c|c|c|c|c|c|c|}
\hline $\mathrm{T},{ }^{\circ} \mathrm{C}$ & 1000 & 1200 & 1400 & 1600 & 1800 & 2000 & 2200 & 2400 & 2600 & 2800 & 3000 \\
\hline Qud, $k W h / k g$ & 0,40 & 0,685 & 0,98 & 1,37 & 1,71 & 1,874 & 1,96 & 2,7 & 2,16 & 2,32 & 2,76 \\
\hline $\mathrm{P}, \mathrm{kW}$ & 65 & 70,3 & 81,4 & 98,1 & 114,75 & 148,1 & 159,2 & 187 & 200 & 225,9 & 292 \\
\hline
\end{tabular}

temperature and melting resulting in chemical transformations to establish thermodynamic equilibrium in the system. The expression for $\mathrm{Q}$ (specific) is:

$$
Q_{S P}=\mathrm{I}_{\text {eq }}-\mathrm{I}_{\text {initial }} \quad, \mathrm{KWh} / \mathrm{kg} \text {, }
$$

Where I (initial) and I (equilibrium) - total enthalpy, referred to $1 \mathrm{~kg}$ of the working fluid (charge + oxidizer), in the initial and equilibrium (after all transformations) states.

For specific thermodynamic systems the I (equilibrium) value is calculated by the method of chemical thermodynamics of multicomponent heterogeneous systems using the TERRA program. The enthalpy of the raw material can be formulated as follows:

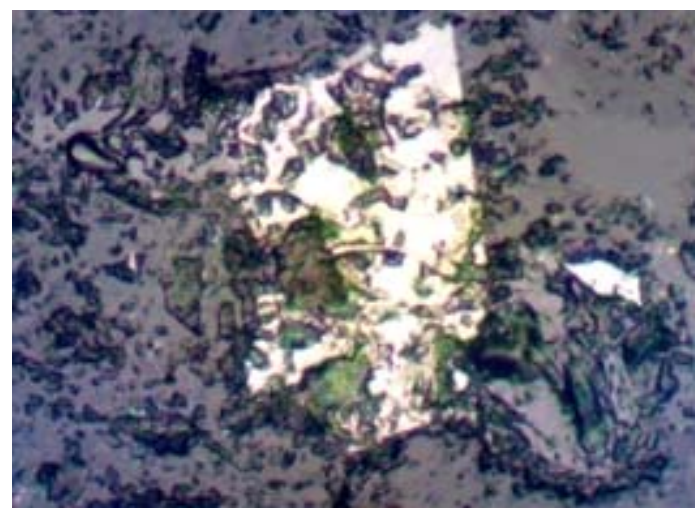

Fig. 1(a). Selendumsky basalt. The texture is massive. Cross polars. Increase. x100; and allocation of porphyritic clinopyroxene partially substituted by chlorite in plagioclase basis;

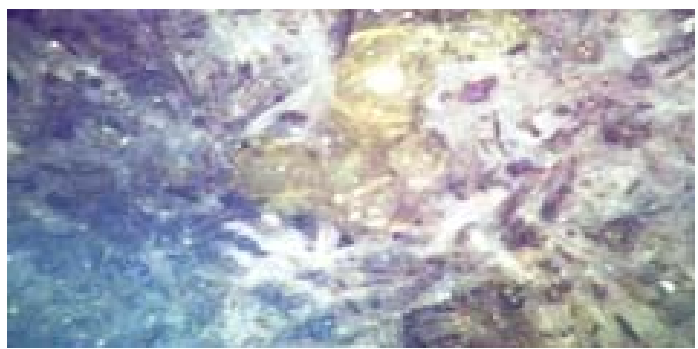

Fig. 1(b). Allocation of olivine surrounded by microlite and volcanic glass

$$
\mathrm{I}_{\text {initial }}=\Delta \mathrm{H}_{\mathrm{f}}^{\circ}\left(\mathrm{T}_{0}\right)_{\text {initial }}+\int_{\text {Tinitial }}^{T o} C p(T) d T, \ldots
$$

Where $\Delta \operatorname{Hof}(\mathrm{T} 0)$ initial - standard heat of formation of the working fluid, T0 $=298,15 \mathrm{~K}$ standard temperature; Tiskh - initial temperature of the process at which the reagents enter the reaction zone.

In case of equality $\mathrm{T}$ initial $=\mathrm{T} 0$, the expression has the form:

$$
\mathrm{I}_{\text {initial }}=\Delta \mathrm{H}_{\mathrm{f}}^{\circ}(298)_{\text {initial }}
$$

Then, it is necessary to determine $\mathrm{I}_{\text {initial }}$ of the system with the reference data thus the enthalpies of formation of all components included in the raw material composition (basalt) are summed $\mathrm{up} \Delta \mathrm{H}_{\mathrm{f}}^{\circ}(298)_{\text {initial }}=\Delta \mathrm{H}_{\mathrm{f}}^{\mathrm{o}}(298)_{\mathrm{SiO} 2}+\Delta \mathrm{H}_{\mathrm{f}}^{\circ}(298)_{\mathrm{Al} 2 \mathrm{O} 3}+$

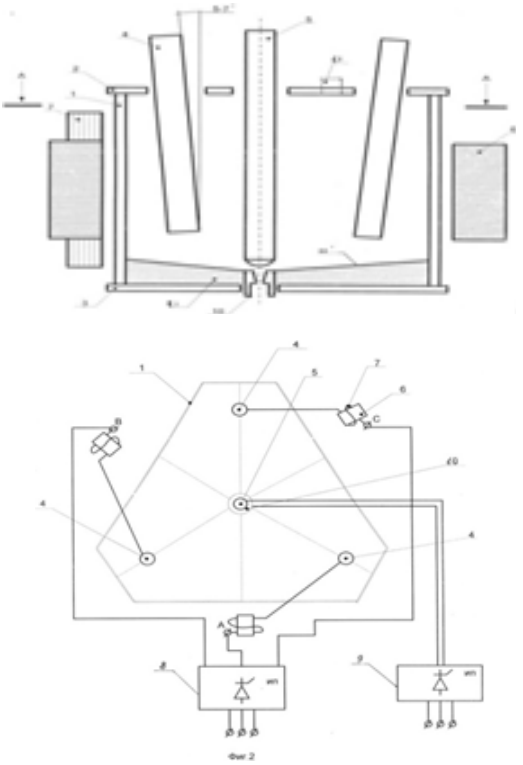

1 - reaction chamber; 2 - water-cooled cover; 3 - watercooled bottom; 4 - rod electrodes (3 pcs.); 5 - locking rod electrode; 6 - pole piece; 7 - series winding; 8 - power source; 9 - additional power for stream heating; 10 device to display melt (taphole); 11 - lined bottom of the chamber; 12 - pipe for supplying the raw material into the reaction chamber; 13 - lining

Fig. 2. Longitudinal (A) and transverse (B) section of the electromagnetic process reactor 
$\Delta \mathrm{H}_{\mathrm{f}}^{\mathrm{o}}(298)_{\mathrm{TiO} 2}+\Delta \mathrm{H}_{\mathrm{f}}^{\mathrm{o}}(298)_{\mathrm{Fe} 2 \mathrm{O} 3}+\Delta \mathrm{H}_{\mathrm{f}}^{\mathrm{o}}(298)_{\mathrm{CaO}}+$ $\Delta \mathrm{H}_{\mathrm{f}}^{\mathrm{o}}(298)_{\mathrm{MgO}}+\Delta \mathrm{H}_{\mathrm{f}}^{\mathrm{o}}(298)_{\mathrm{Na} 2 \mathrm{O}}+\Delta \mathrm{H}_{\mathrm{f}}^{\mathrm{o}}(298)_{\mathrm{K} 2 \mathrm{O}}$ $+\Delta \mathrm{H}_{\mathrm{f}}^{\mathrm{o}}(298)_{\mathrm{MnO}}+\Delta \mathrm{H}_{\mathrm{f}}^{\mathrm{o}}(298)_{\mathrm{P} 2 \mathrm{O} 5}+\Delta \mathrm{H}_{\mathrm{f}}^{\mathrm{o}}(298)_{\mathrm{SO} 3}$

When determining the enthalpy of formation of the components of the system with the above indicated dependence, the value is acquired $\mathrm{I}_{\text {initial }}=112,074.3 \mathrm{~kJ} / \mathrm{kg}$.

When calculating $\mathrm{Q}$ (specific) the mass fractions of the composition components must be also taken into account ${ }^{8}$.

Thus, Selendumsky deposit basalt is the raw material, the mass fractions forming its components composition are distributed in the following way: $\mathrm{SiO}_{2}=0,4812 ; \mathrm{Al}_{2} \mathrm{O}_{3}=0,1387 ; \mathrm{TiO}_{2}$

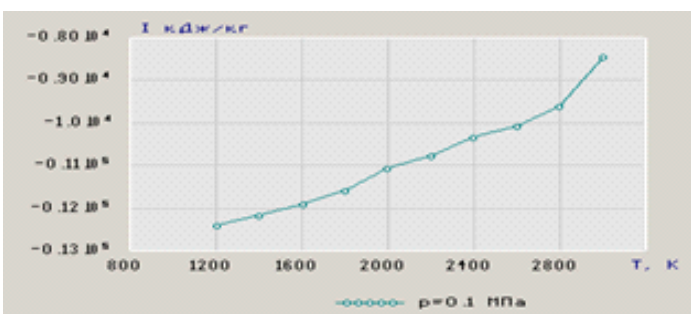

a)

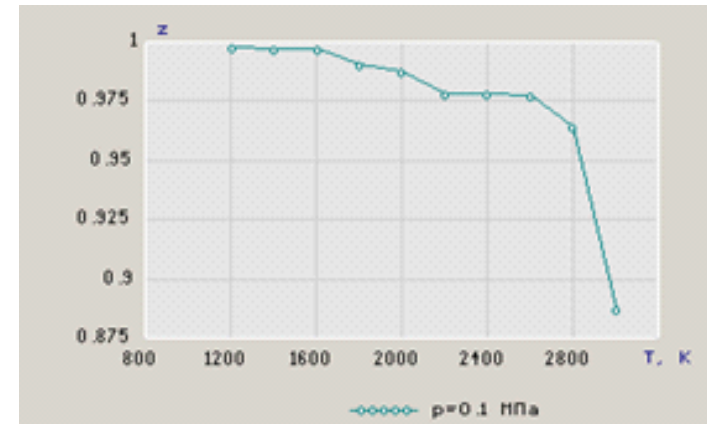

b)

Fig. 3. Complete melting enthalpy (A) and the amount of the condensed phase (B) Selendumsky basalt

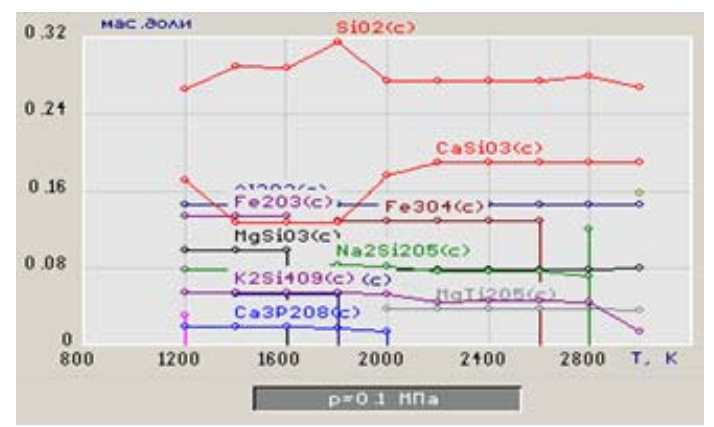

Fig. 4. The composition of the condensed phase of the Selendumsky basalt deposit
$=0,0293 ; \mathrm{Fe}_{2} \mathrm{O}_{3}=0,0528 ; \mathrm{FeO}=0,0674 ; \mathrm{CaO}=$ 0,0880; $\mathrm{MgO}=0,0375 ; \mathrm{Na}_{2} \mathrm{O}=0,0337 ; \mathrm{K}_{2} \mathrm{O}=0,0172$; $\mathrm{P}_{2} \mathrm{O}_{5}=0,0078 ; \mathrm{SO}_{3}=0,0021 ; \mathrm{MnO}=0,17$.

We determine Q(specific) (kWh / kg), and calculate minimal installed electrical power Pel in $\mathrm{kW}$ : The results of thermodynamic calculation of the total enthalpy Iinitial, the amount of the condensed phase Z (\%), as well as the equilibrium composition using the TERRA program are presented in Figures 3, 4 and Table 3.

Calculations have shown that in the condensed phase at temperatures $\mathrm{T}=1000-1800^{\circ}$ $\mathrm{C}$ the concentration of silicon oxide $\mathrm{SiO}_{2}$ monotonically increases from 26.5 to $31.4 \%$, and at $\mathrm{T}=2000^{\circ} \mathrm{C}$ is reduced to $27.4 \%$ due to $\mathrm{CaSiO} 3$ increasing concentration and at $\mathrm{T}=3000^{\circ} \mathrm{C}$ is 26.6\%, and alumina $\mathrm{Al}_{2} \mathrm{O}_{3}$ remains almost constant and is $14.4 \%$. Mono calcium silicate $\mathrm{CaSiO}_{3}$ in the temperatures range of $1400-1800{ }^{\circ} \mathrm{C}$ is reduced to $12.6 \%$, this is due to the formation of $\mathrm{CaTiO}_{3}(5,2 \%)$ in this range and the fall to zero concentration of $\mathrm{TiO} 2$. Then there is a gradual increase of $\mathrm{CaSiO} 3$ concentration and at $2000{ }^{\circ} \mathrm{C}$ it is equal to the initial value. This is because at a temperature of $2000^{\circ} \mathrm{C} \mathrm{MgTi} 2 \mathrm{O} 5$ is formed with the concentration $3.8 \%$. This is explained by the formation at the given temperature of $\mathrm{CaTiO} 3(1,2 \%) . \mathrm{MgSiO}_{3}$ concentration is $9.7 \%$, and then at $1800^{\circ} \mathrm{C}$ it falls to zero. This is due to the formation of $\mathrm{Mg}_{2} \mathrm{SiO}_{4}$. At $2000^{\circ} \mathrm{C}$ the concentration of $\mathrm{MgSiO} 3$ is aligned and is $7.8 \%$. When heated to the temperature of $1600^{\circ} \mathrm{C} \mathrm{Fe}+3$ is oxidized to $\mathrm{Fe}+4$, and then at the temperature of $2800^{\circ} \mathrm{C}$ cation reduction process is observed, $\mathrm{Fe}+4$ to $\mathrm{Fe}+2$ and at $3000^{\circ} \mathrm{C}$ transition to $\mathrm{Fe} 2 \mathrm{SiO}_{4}$.

The dependence of the specific energy consumption of the temperature is shown in Table 4.

\section{CONCLUSION}

Thus, summarizing the content of the article it should be noted that the temperature range, and the specific energy consumption of hightemperature processing (melting) of basalt were specified. The analysis showed that the optimal temperature range of the melting point of these materials is in the range of $1400-1600^{\circ} \mathrm{C}$, and the specific energy consumption in average 1.1-1.3 $\mathrm{kWh} / \mathrm{kg}$. According to the experimental data the 
installation power depending on the raw material composition ranges from 65 to $200 \mathrm{~kW}$, at a production rate of $150 \mathrm{~kg}$ of melt / h [9]. The data for the electric arc plasma reactor power calculated by thermodynamic calculation agrees with the experimental data. Thus, a good melt flow of basalt without additional charging is observed at $1600^{\circ}$ C. The measurement was carried out at the stream output from the tap hole using near infrared hightemperature optical pyrometer ( $\tilde{A} 1$ micron). The electric power of the reactor during the melting was in the range of $65-200 \mathrm{~kW}$. The specific power consumption data refer only to the melt, and therefore does not include the power consumption for the latent heat of melting, supporting facilities and other factors.

The presented electric arc melting reactor, which is a type of plasma reactors, let smoothly regulate the temperature of the melt and maintain the stream output from the tap hole, which made it possible to reduce the viscosity and increase the melt flow.

The generated melt can be recommended for generating of stony casting and thin mineral fibers as a component of composite materials, and generating of fibrous heat insulating materials.

It should be noted that the fibers produced from molten basalt and artificial mixture of the same composition, exhibit different physical and mechanical properties. Probably, in the basalt melting a liquid with particles located close to the original crystal pattern is formed, which remains in the fibers formation ${ }^{10}$.

\section{REFERENCES}

1. Myasnikov AA, MS Aslanova Composition selection of basalt rocks to produce fibers for various purposes // Glass and Ceramics, 1965; 3: $12-15$.

2. Buyantuev SL, Sultimova VD Dondokov A.TS., Volokitin GG, Zayahanov ME, Tsyrenov SA Production of constructional heat insulating materials using plasma treatment// Building Complex of Russia: Science, Education, Practice: Proceedings of Intern. scientific. conf. Ulan-Ude, 2006; 90-93.

3. Zavaritskii AN Sobolev VS Physical and chemical basis of igneous rocks petrography. M . Gosgeologtehizdat, 1961; 384 .

4. R. Stoiber, C. Morse Detection of crystals under microscope. - M .: Mir, 1974; 282 p.

5. Dzhigiris DD, Macha MF Production basics of basalt fibers and basalt products. - M .: Heat and Power Engineering, 2002; 416.

6. Kutolin VA Petrochemistry and petrology issues of basalts. Publishing House "Nauka” Siberian Branch. Novosibirsk. 1972; 208.

7. BG Trusov TERRA program for calculation of plasma-chemical processes // Proc. 3 Intern. Symp. on Theoretical and Applied Plasma Chemistry. Ples, 2002; 217-218.

8. Vatolin NA BG Trusov, GK Moiseev Thermodynamic modeling in inorganic systems of high temperature. M .: Metallurgy, 1994.

9. Buyantuev SL Fibrous heat insulating materials made of rock melts and technogenic ash and slag waste: monograph / SL Buyantuev, AS Kondratenko. - Ulan-Ude Univ VSGUTU, 2014; 180

10. Dubrovsky, VA .; Rychko VA and others. Basalt melts to form staple fiber // Glass and Ceramics, 1968; 2: 18-20. 